\title{
Compatibility of Amblyseius swirskii with Beauveria bassiana: two potentially complimentary biocontrol agents
}

by Midthassel, A., Leather, S.R., Wright, D.J. and Baxter, I.H.

Copyright, Publisher and Additional Information: open access publisher's manuscript published by Springer under the terms of Creative Commons Attribution 4.0 International License http://creativecommons.org/licenses/by/4.0

DOI: $10.1007 / \mathrm{s} 10526-016-9718-3$

Harper Adams

University 


\title{
Compatibility of Amblyseius swirskii with Beauveria bassiana: two potentially complimentary biocontrol agents
}

\author{
Audun Midthassel - Simon R. Leather • \\ Denis J. Wright • Ian H. Baxter
}

Received: 23 September 2015/ Accepted: 26 January 2016

(C) The Author(s) 2016. This article is published with open access at Springerlink.com

\begin{abstract}
The two biocontrol agents Amblyseius swirskii Athias-Henriot (Acari: Phytoseiidae) and Beauveria bassiana (Balsamo) Vuillemin (Hypocreales: Cordycipitaceae) have the potential to complement one another as part of an integrated pest management programme. While both can suppress whitefly and thrips infestations in protected crops, A. swirskii is primarily used preventatively whereas $B$. bassiana can be used as a curative treatment at higher pest levels. With this concomitant use in mind, the research presented here aimed to identify potential negative effects of the commercial B. bassiana strain GHA on A. swirskii in a laboratory study. Adult A. swirskii were found to be susceptible to $B$. bassiana infection with slight to moderate virulence $(20.74 \pm 3.89$ to $48.33 \% \pm 3.07)$ depending on the type of exposure and with a reduction in fecundity over time. There was however no negative effect on juvenile survival neither on dry residue nor on
\end{abstract}

Handling Editor: Nicolai Meyling.

A. Midthassel $(\bowtie) \cdot$ I. H. Baxter

R\&D Department, Certis Europe UK, Granta Park,

Cambridgeshire CB21 6AD, UK

e-mail: midthassel@certiseurope.com

\section{A. Midthassel - D. J. Wright}

Department of Life Sciences, Imperial College London, Silwood Park Campus, Ascot SL5 7PY, UK

\section{S. R. Leather}

Department of Crop \& Environment Sciences, Harper

Adams University, Edgmond, Newport TF10 8NB, UK the offspring of infected mites. Thus, these two biocontrol agents do have the potential to be complementary. Further trials in the field are still required before a final conclusion can be reached.

Keywords Integrated pest management - Mites · Phytoseiidae $\cdot$ Entomopathogens $\cdot$ Sublethal effects

\section{Introduction}

Augmentative biocontrol in protected crops often involves multiple biological control agents (BCAs) targeting the same or different pest species (Wittman and Leather 1997; Shipp et al. 2003; Calvo et al. 2009; Labbe et al. 2009; Chow et al. 2010; Messelink et al. 2011). These BCAs may also be used in conjunction with biorational chemicals in integrated pest management (IPM) programmes where the focus is to combine crop protection strategies with the overall aim to reduce the use of broad spectrum pesticides and chemical residues on produce (Cock et al. 2010). Combining several BCAs may allow a holistic biological pest management programme but interactions between different BCAs are complex and one species can potentially disrupt the functions of another. Biocontrol programmes can be compromised due to competition or intraguild predation (e.g. hyperpredation, hyperparasitism and pathogenicity) from other introduced BCAs or naturally occurring 
species (Momen and Abdel-Khalek 2009; Chow et al. 2010; Buitenhuis et al. 2010; Messelink et al. 2011; Shipp et al. 2012; da Silva et al. 2015). In order to develop efficient and successful pest management programmes compatibility between the different BCAs must be established.

Phytoseiid mites are important components of pest management programmes in protected crops and one of the most widely used species is Amblyseius (=Typhlodromips) swirskii Athias-Henriot (Acari: Phytoseiidae) (van Lenteren 2012). Marketed primarily for whitefly (Hemiptera: Aleyrodidae) and thrips (Thysanoptera: Thripidae) control, both of which are major pests in tomatoes, peppers, cucumbers and ornamentals (Malais and Ravensberg 2003), this polyphagous predator can suppress pest outbreaks on its own (Messelink et al. 2006; Chow et al. 2010; Messelink et al. 2010; Calvo et al. 2011). Combining its use with other BCAs can enhance pest control particularly when the BCAs do not compete directly but exploit different life stages of the same pest (Calvo et al. 2009; Dogramaci et al. 2011). Conversely, A. swirskii can interfere with other BCAs by inter- and intraguild predation (hyperpredation) (Buitenhuis et al. 2010; Messelink et al. 2011). In the field, A. swirskii is primarily used preventatively to avert pest establishment and for controlling light whitefly and thrips infestations (Messelink et al. 2010; Calvo et al. 2011). At high pest pressure, curative control by predatory mites is often insufficient and corrective applications with chemical pesticides or biopesticides may be required (Calvo et al. 2009; Medd and GreatRex 2014). Ideally, the products used for corrective treatments should have minimal impact on other BCAs present in the crop.

The fungal entomopathogen Beauveria bassiana (Balsamo) Vuillemin (Hypocreales: Cordycipitaceae) exhibits a wide host range and several strains have been developed as commercial mycoinsecticides (de Faria and Wraight 2007; Zimmermann 2007). Commercial formulations of $B$. bassiana are used curatively to suppress larger outbreaks of arthropod pests (Wraight et al. 2000; Faria and Wraight 2001; Inglis et al. 2001; Jacobson et al. 2001; Shipp et al. 2003). As both $A$. swirskii and B. bassiana target whitefly and thrips, it is natural to consider them as potentially complementary intraguild BCAs: A. swirskii for preventative control and $B$. bassiana for curative control.
Due to its wide host range, $B$. bassiana may have detrimental effects on beneficial arthropods but this will depend on pathogen strain and host species (Seiedy et al. 2015). For instance, B. bassiana has been found to be infectious to hymenopteran parasitoids (Ludwig and Oetting 2001; Shipp et al. 2003) and may potentially disrupt their biocontrol functions. Despite the wide host range of $B$. bassiana, pathogenicity has only been reported to relatively few species of mites (Chandler et al. 2000).

Interactions between arthropods and entomopathogens are however complex (Agboton et al. 2013; Aqueel and Leather 2013) and the impact of sublethal effects is poorly understood (Pozzebon and Duso 2010; Seiedy et al. 2012; Shipp et al. 2012). The aim of this study was to establish the potential of the commercially available $B$. bassiana strain GHA to infect and kill $A$. swirskii under optimal conditions for the pathogen and to investigate the effects on specific population parameters when subjected to topical application of B. bassiana conidial suspensions and/ or dry residues on leaf discs.

\section{Materials and methods}

Mite cultures

Amblyseius swirskii were acquired from a commercial culture at BCP Certis (Kent, UK) and reared on $50 \mathrm{~mm}$ French dwarf bean, Phaseolus vulgaris L. leaf discs at $25{ }^{\circ} \mathrm{C}, 70 \% \mathrm{RH}$ and 16:8 L:D. Cattail pollen (Typha sp.) was provided as a food source ad libitum.

Fungal cultures

Laboratory cultures of B. bassiana strain GHA were established from the commercial product BotaniGard ${ }^{\circledR}$ 22 WP (Laverlam International Corporation, USA) by spread-plating $100 \mu \mathrm{l}$ of a $0.0625 \%$ suspension onto Sabouraud Dextrose Agar (SDA) in $90 \mathrm{~mm}$ diameter Petri dishes. Cultures were incubated in darkness at $25{ }^{\circ} \mathrm{C}$ and $75 \% \mathrm{RH}$ for 14 days. Sub-cultures were prepared by spread-plating $100 \mu \mathrm{l}$ conidial suspensions.

Preparation of conidial suspensions

Following 14 days of incubation, the $B$. bassiana cultures were dried by removing the Petri dish lid and 
placing the cultures in $25{ }^{\circ} \mathrm{C}$ and $40 \% \mathrm{RH}$ for $18 \mathrm{~h}$ (Baxter 2008). Conidia were dislodged and collected by tapping the Petri dish containing the culture into a sterile glass funnel (100 $\mathrm{mm}$ diameter) leading to a sterile $50 \mathrm{ml}$ glass bottle. The conidia collected from 10 plates were suspended in $5 \mathrm{ml}$ sterile water with $0.02 \%$ Tween $^{\circledR} 80$, and vortex mixed for $2 \mathrm{~min}$ (Mascarin et al. 2013). Conidial suspensions were prepared from dried cultures to represent the conidia from the dry formulation of the commercial product.

The concentration of conidia was assessed using a Neubauer Haemocytometer $0.1 \mathrm{~mm}$ (Hawksley, UK). Conidial suspensions were diluted to $2.5 \times 10^{7}$ and $1 \times 10^{8}$ conidia $\mathrm{ml}^{-1}$, representing the lowest and highest recommended rates, for whitefly and thrips respectively, according to the BotaniGard ${ }^{\circledR} 22 \mathrm{WP}$ label. Six replicate conidial suspensions were prepared per treatment for each experiment.

To estimate viability of the conidia, $10 \mu \mathrm{l}$ of the conidial suspension was applied onto a thin layer of SDA on one microscope slide per replicate conidial suspension $(n=6)$ placing a cover slip on top (Bugeme et al. 2008). The slides were incubated in darkness at $25{ }^{\circ} \mathrm{C}, 75 \% \mathrm{RH}$ for $18 \mathrm{~h}$. Germination rate was estimated by assessing 100 conidia in four different fields of view per slide (Liu et al. 2003). Viability was $>95 \%$ in all experiments.

\section{Bioassays}

Female adults of A. swirskii, age 2-4 days, were exposed to $B$. bassiana by topical application, dry residue on $P$. vulgaris leaf discs or a combined exposure with topical application followed by dry residue exposure, inspired by the methods of Dennehy et al. (1993) and Pozzebon and Duso (2010) as described below. The trial arenas (leaf discs in $50 \mathrm{~mm}$ Petri dishes) were incubated at $25{ }^{\circ} \mathrm{C}, 90 \% \mathrm{RH}$ and 16:8 L:D to maximise the likelihood of fungal infection.

Topical application of $A$. swirskii females was conducted by immersing 10 mites individually in $1 \mathrm{ml}$ of $B$. bassiana conidial suspensions of $2.5 \times 10^{7}$ or $1 \times 10^{8}$ conidia $\mathrm{ml}^{-1}$ in a Petri dish for $30 \mathrm{~s}$. The mites were then placed on filter paper to drain off excess liquid prior to transfer onto leaf discs using a fine brush. This procedure was replicated six times, hence 60 mites were tested per treatment. Control mites were immersed in a $0.02 \%$ Tween ${ }^{\circledR} 80$ solution.
Pollen (Typha sp.) was provided as a food source in all treatments throughout the experiments.

Dry residues of $B$. bassiana were prepared by immersing $50 \mathrm{~mm}$ leaf discs in $10 \mathrm{ml}$ conidial suspensions of $2.5 \times 10^{7}$ or $1 \times 10^{8}$ conidia ml $^{-1}$, and $0.02 \%$ Tween ${ }^{\circledR} 80$ for the control, for $30 \mathrm{~s}$ and air drying them for $1 \mathrm{~h}$. The mites in the dry residue and combined exposure trials were allowed to forage on $B$. bassiana residues for four days (Bugeme et al. 2008), representing the persistence of conidia on the top leaves of a plant in the field (Inglis et al. 1993).

Survivorship and fecundity were monitored once per day for 10 days, removing the eggs from the leaf discs each day. On day 1, 4, 7 and 10 post-treatment, eggs were collected from each leaf disc using a fine brush and placed onto untreated leaf discs. The offspring were monitored for six days recording egg viability, juvenile survival and sex ratio.

Dead mites were transferred to Petri dishes with moistened filter paper to encourage sporulation. Death by mycosis was confirmed by sporulation or red colouration of cadavers. The identity of the fungal growth on cadavers was confirmed by microscopic investigation of lactophenol blue stained conidiophores and conidia at magnification $\times 400$, according to Humber (1997).

The effect of $B$. bassiana residues on juvenile $A$. swirskii was studied to simulate the impact on new founding populations of mites dispersing into a newly treated crop. Ten gravid A. swirskii were allowed to oviposit on dry residue of the conidial suspensions, or $0.02 \%$ Tween $^{\circledR} 80$ as a control, for $16 \mathrm{~h}$. The eggs deposited were corrected to 15 per replicate leaf disc $(n=6)$ and reared to adulthood for six days on the dry residue, recording egg viability and juvenile survival. Six days was sufficient for all mites to have reached maturity and to have mated. The surviving adult females were transferred to clean leaf discs and monitored for a further 10 days for survivorship and fecundity.

\section{Data analysis}

Survival rates were estimated by parametric survival analysis with the Weibull distribution, due to nonconstant hazards, in the R 3.1.2 statistical package ( $R$ Core Team 2012), which generates $z$ values as a result of Wald tests. Multiple comparisons were conducted 
using Tukey's post-hoc in the multcomp package in $\mathrm{R}$ (Hothorn et al. 2008).

Fecundity rates were analysed using generalized linear mixed models (GLMM) with binomial errors, which uses the logit link function, in the lme4 package in $\mathrm{R}$, where the proportion is the total number of eggs on a given day in a replicate leaf disc to the total population (number of surviving female mites + number of eggs) in that leaf disc on that day. Treatment was set as the fixed effect and replication and time (days numerated 1-10) as random effects. GLMM analysis allows comparisons of change in fecundity among treatments over time. Trend lines were plotted using generalised additive models (GAM).

Egg viability, juvenile survival and sex ratio of offspring was analysed by generalized linear models (GLM) with binomial errors, which uses the logit link function to transform the data. This generates $z$ values as a result of Wald tests. Tukey's post-hoc analysis was conducted to identify significant differences between treatments.

\section{Results}

\section{Survivorship}

The B. bassiana treatments had a significant effect on the survival rates of adult $A$. swirskii compared with the control treatment. On dry residue the suspension with $1 \times 10^{8}$ conidia $\mathrm{ml}^{-1}$ significantly reduced survival compared with the control treatment $(z=2.97$, $\mathrm{p}<0.01$ ). There was no significant difference between this treatment and the $2.5 \times 10^{7}$ conidia $\mathrm{ml}^{-1}$ treatment $(z=1.77, \mathrm{p}=0.18)$, nor between the latter and the control $(z=1.76, \mathrm{p}=0.18)$ (Fig. 1a).

Topical application of $B$. bassiana significantly reduced the survival rates of adult $A$. swirskii for both $2.5 \times 10^{7}(z=2.92, \mathrm{p}<0.01)$ and $1 \times 10^{8}$ conidia $\mathrm{ml}^{-1}(z=3.70, \mathrm{p}<0.001)$ compared with the control treatment. There was no significant difference $(z=1.53, \mathrm{p}=0.27)$ between the two $B$. bassiana treatments (Fig. 1b).

Combined exposure to topical application and dry residue of $B$. bassiana significantly reduced the survival rates of adult $A$. swirskii for both $2.5 \times 10^{7}$ $(z=3.39, \mathrm{p}<0.01)$ and $1 \times 10^{8}$ conidia $\mathrm{ml}^{-1}$ $(z=3.68, \mathrm{p}<0.001)$ compared with the control treatment. There was no significant difference between the two $B$. bassiana treatments $(z=0.92$, $\mathrm{p}=0.61)$ (Fig. 1c).

Beauveria bassiana did not have a significant effect on survival rates of juvenile A. swirskii reared from egg to adult on dry residue and monitored for a further 10 days after final ecdysis (Fig. 1d). There was no treatment effect on egg viability and juvenile survival was similar in all treatments.

The scale parameter was $<1$ in all experiments indicating that the risk of dying decreases with time (Crawley 2007). This suggests the time frame of observation (10 days) was sufficient to capture the majority of the mites dying as a result of the treatment.

Mites with confirmed mycosis were observed in all $B$. bassiana treatments except with juveniles reared on the dry residue of the conidial suspension with $2.5 \times 10^{7}$ conidia $\mathrm{ml}^{-1}$. Dead mites exhibited pink to dark red colouration after death followed by sporulation. No mycosis was observed in the control treatments.

\section{Fecundity}

The oviposition rate decreased with time in all treatments and the number of eggs deposited per surviving female per day decreased at a higher rate for A. swirskii treated with $B$. bassiana than control mites (Fig. 2a-d). Exposing adult $A$. swirskii to dry residue of $B$. bassiana did not have a significant effect on fecundity (Fig. 2a). Juvenile A. swirskii exposed to dry residues however exhibited a significant decrease in fecundity in the subsequent mature life stage for $1.0 \times 10^{8}(z=3.90, \mathrm{p}<0.001)$ and $2.5 \times 10^{7}$ conidia $\mathrm{ml}^{-1}(z=2.62, \mathrm{p}<0.05)$ (Fig. $\left.2 \mathrm{~d}\right)$.

For adult mites exposed to topical and combined treatments there was a significant effect on fecundity at $2.5 \times 10^{7}(z=2.38, \mathrm{p}<0.05)$ and $1.0 \times 10^{8}$ conidia $\mathrm{ml}^{-1}(z=4.49, \mathrm{p}<0.001)$, respectively. Treatments with $1.0 \times 10^{8}$ and $2.5 \times 10^{7}$ conidia $\mathrm{ml}^{-1}$ did not exhibit a significant effect on fecundity for topical $(z=2.27, \quad \mathrm{p}=0.06) \quad$ (Fig. 2b) and combined $(z=1.76, \mathrm{p}=0.18$ ) exposure (Fig. $2 \mathrm{c}$ ) respectively, due to within-group variation in the data.

\section{Offspring}

Egg viability, juvenile survival and sex ratio of the offspring from B. bassiana-treated adult $A$. swirskii are summarised in Table 1. As there were no differences in any of the measured parameters between sampling 

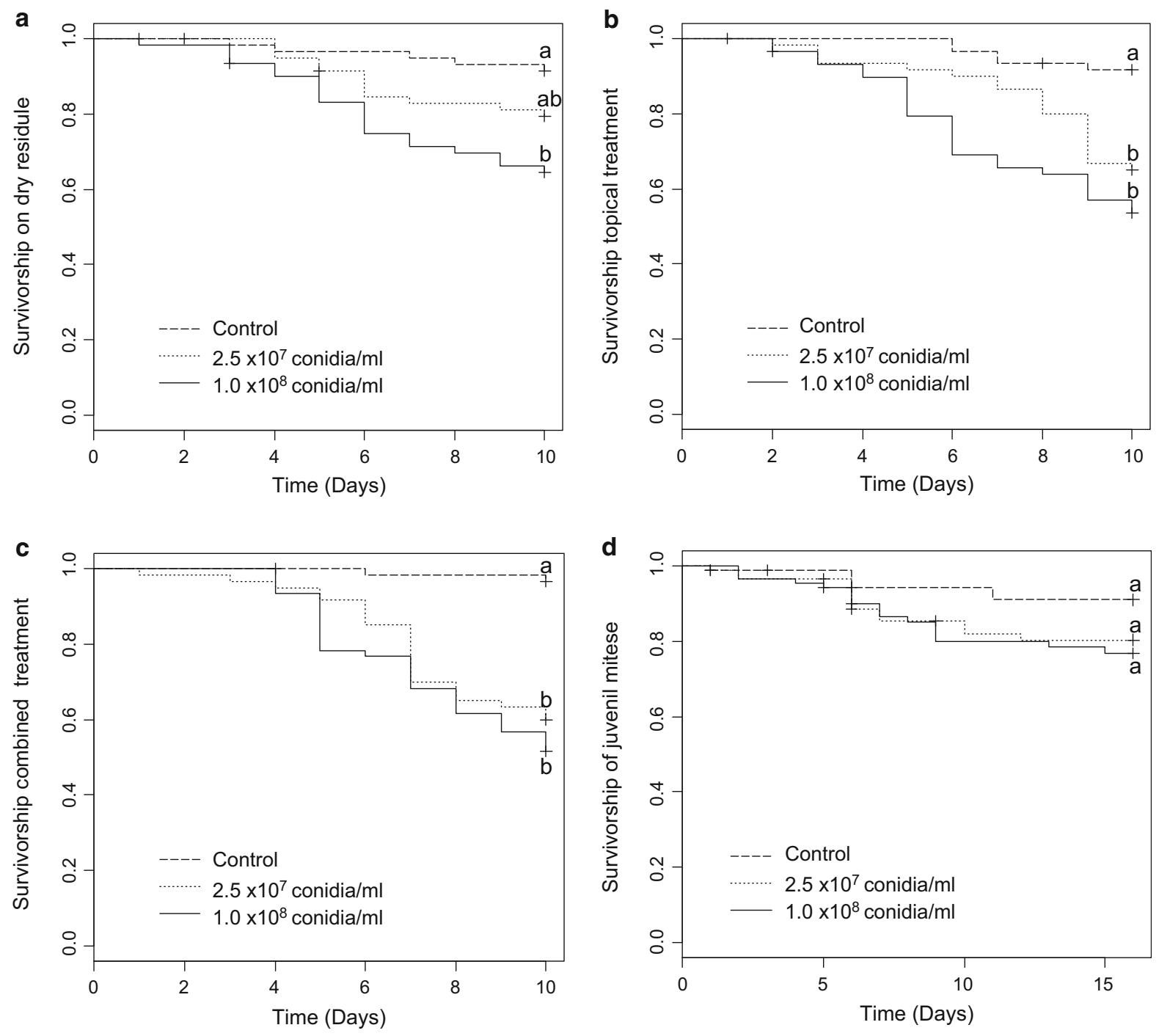

Fig. 1 Survivorship of Amblyseius swirskii adults exposed to a dry residue, $\mathbf{b}$ topical treatment, c combined treatment, and d juveniles on dry residue of Beauveria bassiana conidial suspensions $(n=6)$. Different letters indicate significant

days of the same treatment these have been combined. Treating mites with $B$. bassiana had no observable or measurable effect on their offspring and there were no significant differences between the offspring of treated mites and the control (Table 2a-c).

\section{Discussion}

Beauveria bassiana strain GHA was found to be infectious to A. swirskii when exposed to topical

difference in survival rate as analysed by the Weibull distribution and compared using Tukey's post-hoc $(\mathrm{p}<0.05)$. The ' + ' signs indicate censoring, i.e. mites that are missing or survived the observation period

application and/or dry residues under laboratory conditions with slight to moderate virulence (according to the IOBC toxicity classes). The topical treatment was intended to simulate the effect on a mite population in the crop directly exposed to a $B$. bassiana application followed by dispersal to untreated leaves or new growth. The dry residue exposure simulated mites dispersing into a recently treated crop whereas the combined exposure simulated the effect on mites exposed directly to the spray application and remaining on the treated leaves. 

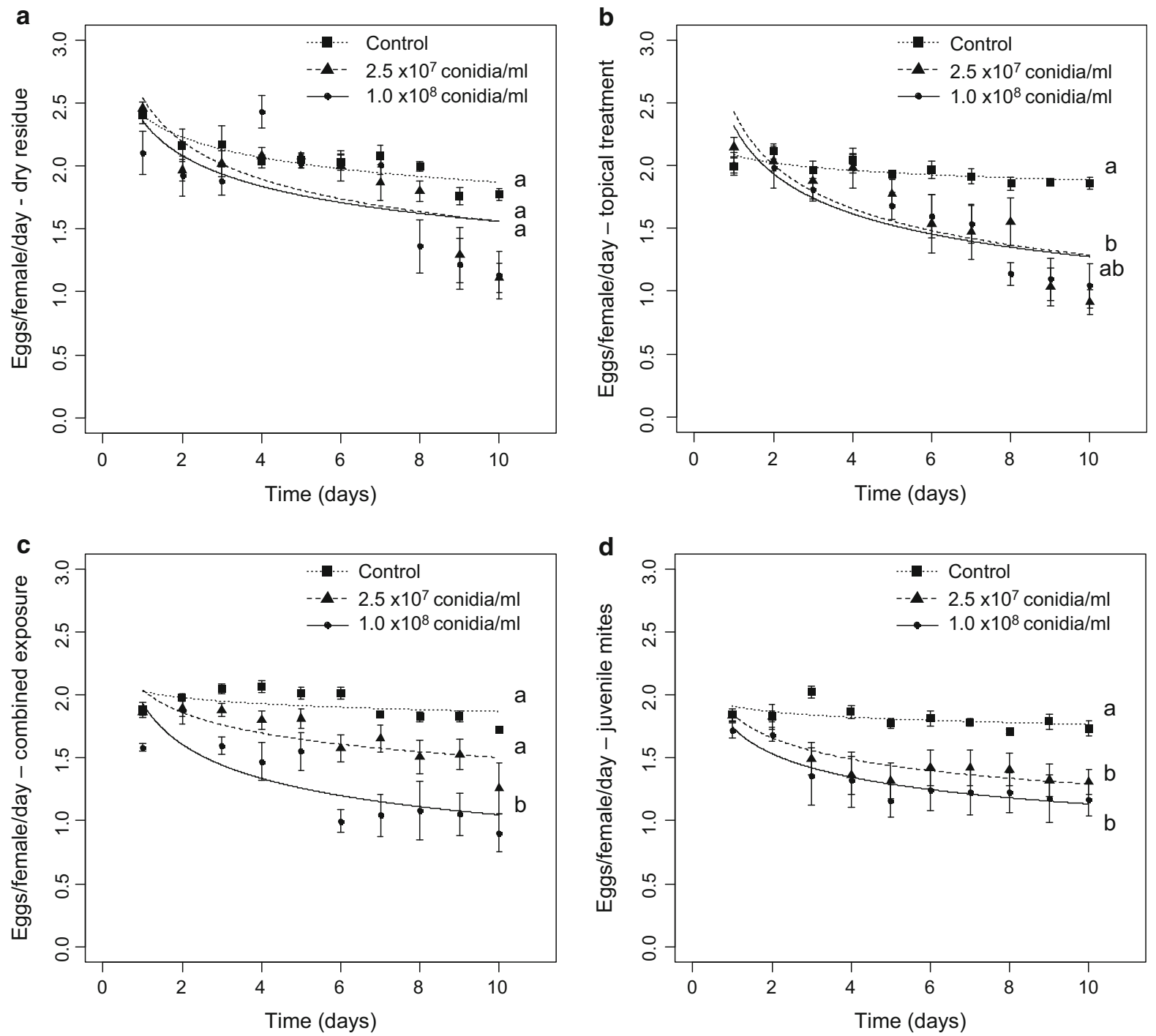

Fig. 2 Mean daily fecundity of Amblyseius swirskii adults exposed to a dry residue, b topical treatment, c combined treatment, and $\mathbf{d}$ juveniles on dry residue of Beauveria bassiana conidial suspensions $(n=6)$. Error bars represent SE. Different

Exposure of adult $A$. swirskii to $B$. bassiana at both the highest and lowest recommended dose according to the BotaniGard ${ }^{\circledR} 22$ WP label significantly reduced survivorship of A. swirskii compared with the control treatment, indicating a clear treatment effect. There was no significant difference between the two doses applied in terms of survivorship, which is consistent with the results of Numa Vergel et al. (2011) who found no difference in mortality of Neoseiulus

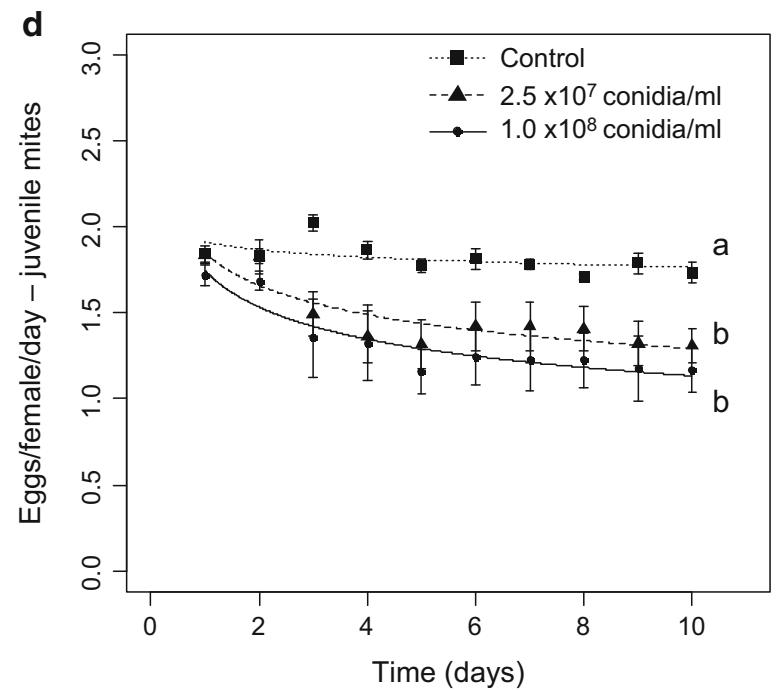

letters indicate significantly different trend in oviposition rates as analysed by generalized linear mixed models and compared using Tukey's post-hoc $(\mathrm{p}<0.05)$. Trend lines were plotted with generalised additive models

californicus and Phytoseiulus persimilis treated with three different doses of $B$. bassiana.

The survival rates of $A$. swirskii exposed to topical treatments of B. bassiana strain GHA corresponds to the mortality rates of $A$. swirskii exposed to $B$. bassiana strain F, as reported by Seiedy et al. (2015). The authors found the virulence of B. bassiana to A. swirskii to be dependent on pathogen strain indicating the importance of studying compatibility 
Table 1 Egg viability, juvenile survival and sex ratio (proportion $\pm \mathrm{SE}$ ) of the offspring from Amblyseius swirskii adults following different treatments of Beauveria bassiana conidial suspensions

\begin{tabular}{|c|c|c|c|c|}
\hline Experiment & Treatment & Egg viability & Juvenile survival & q sex ratio \\
\hline \multirow[t]{3}{*}{ Dry residue } & Control & $1.00 \pm 0.00$ & $0.95 \pm 0.01$ & $0.68 \pm 0.01$ \\
\hline & $2.5 \times 10^{7}$ & $0.99 \pm 0.01$ & $0.93 \pm 0.01$ & $0.69 \pm 0.02$ \\
\hline & $1.0 \times 10^{8}$ & $0.99 \pm 0.00$ & $0.93 \pm 0.02$ & $0.64 \pm 0.02$ \\
\hline \multirow[t]{3}{*}{ Topical } & Control & $1.00 \pm 0.0$ & $0.96 \pm 0.01$ & $0.69 \pm 0.01$ \\
\hline & $2.5 \times 10^{7}$ & $0.99 \pm 0.01$ & $0.95 \pm 0.01$ & $0.69 \pm 0.02$ \\
\hline & $1.0 \times 10^{8}$ & $0.98 \pm 0.01$ & $0.94 \pm 0.01$ & $0.73 \pm 0.02$ \\
\hline \multirow[t]{3}{*}{ Combined } & Control & $1.00 \pm 0.00$ & $0.96 \pm 0.01$ & $0.69 \pm 0.01$ \\
\hline & $2.5 \times 10^{7}$ & $1.00 \pm 0.00$ & $0.95 \pm 0.02$ & $0.68 \pm 0.01$ \\
\hline & $1.0 \times 10^{8}$ & $0.99 \pm 0.01$ & $0.95 \pm 0.01$ & $0.68 \pm 0.02$ \\
\hline
\end{tabular}

with specific strains, particularly commercially available strains such as GHA.

Beauveria bassiana has been found to be infectious to other phytoseiid mites under laboratory conditions. Castagnoli et al. (2005) reported slight mortality of the spider mite predator $N$. californicus when exposed to topical treatment of B. bassiana. However, mortality was assessed after three days, whereas fungal pathogenesis may require several days to kill its host (Inglis et al. 2001; Shah and Pell 2003). Nevertheless, a significantly higher mortality of B. bassiana-treated $N$. californicus compared with the control was reported, with similar survivorship as reported for $A$. swirskii in the present study. Numa Vergel et al. (2011), on the other hand, reported that although $N$. californicus is susceptible to $B$. bassiana, virulence is low $(<30 \%)$ and not different to the control treatment over a 12-day period.

Several studies have found the spider mite predator $P$. persimilis to be susceptible to $B$. bassiana topical treatment and exposure to dry residues under laboratory conditions. The studies reported susceptibility with slight to moderate virulence to $P$. persimilis after observation periods of three days (Duso et al. 2008), six days (Pozzebon and Duso 2010) and 12 days (Numa Vergel et al. 2011). Only Ludwig and Oetting (2001) reported high virulence to $P$. persimilis exposed to topical treatment of B. bassiana with $100 \%$ mortality, although time of death and sporulation was not mentioned. With the exception of the latter, these studies report mortality rates comparable to the effects of B. bassiana to A. swirskii presented here.

Sublethal effects of an entomopathogen on nontarget predators can be manifested by a change in fecundity, predation rates, longevity and fitness of subsequent offspring (Duso et al. 2008; Seiedy et al.
2012; Shipp et al. 2012). There was an overall trend of reduced fecundity in B. bassiana-treated A. swirskii in the present study, except for adult mites exposed to dry residue only, indicating an effect on the fitness of the mites.

Pozzebon and Duso (2010) reported no effect on the fecundity of $P$. persimilis when exposed to dry residue and/or topical treatment of B. bassiana but a significant reduction in eggs deposited was discovered when the mites were exposed to a combination of topical treatment, dry residue and feeding on $B$. bassiana treated prey. Furthermore, Numa Vergel et al. (2011) demonstrated that $B$. bassiana topical treatment had no negative effect on the fecundity of $N$. californicus and $P$. persimilis at three different concentrations. It is therefore reasonable to conclude that $B$. bassiana can reduce the fecundity of phytoseiid mites, including $A$. swirskii, but primarily when experiencing a combination of exposure routes with high conidial concentrations.

Apart from egg viability, the effect of $B$. bassiana on the offspring of treated individuals have not previously been studied for phytoseiid mites. Offspring of arthropods infected with $B$. bassiana may exhibit reduced survival and fecundity, moulting problems and malformations (Torrado-Leon et al. 2006). Egg hatching success can be significantly reduced for gravid $B$. bassiana-treated $N$. californicus (Castagnoli et al. 2005) and $P$. persimilis (Pozzebon and Duso 2010), but, contrary to these findings, treatment of $P$. persimilis with $B$. bassiana has also been reported to have no effect on egg hatching success (Duso et al. 2008; Seiedy et al. 2012). The results of the current study are consistent with the latter: no significant effect was observed on egg viability, juvenile survival or the sex ratio of offspring 
Table 2 Overview of results from GLM analyses with binomial errors and Tukey's post-hoc for multiple comparison for a egg viability, b juvenile survival and $\mathbf{c}$ sex ratio of offspring from adult Amblyseius swirskii exposed to treatments of Beauveria bassiana

\begin{tabular}{|c|c|c|c|c|}
\hline \multirow[t]{2}{*}{ Treatments } & \multicolumn{2}{|c|}{ Control } & \multicolumn{2}{|c|}{$\begin{array}{l}2.5 \times 10^{7} \\
\text { conidia } \mathrm{ml}^{-1}\end{array}$} \\
\hline & $z$ & $\mathrm{P}$ & $z$ & $\mathrm{P}$ \\
\hline \multicolumn{5}{|l|}{ a } \\
\hline \multicolumn{5}{|l|}{ Dry residue } \\
\hline $1.0 \times 10^{8}$ conidia $\mathrm{ml}^{-1}$ & 1.68 & 0.21 & 0.78 & 0.71 \\
\hline $2.5 \times 10^{7}$ conidia $\mathrm{ml}^{-1}$ & 1.10 & 0.51 & & \\
\hline \multicolumn{5}{|l|}{ Topical treatment } \\
\hline $1.0 \times 10^{8}$ conidia $\mathrm{ml}^{-1}$ & 1.59 & 0.25 & 0.12 & 0.99 \\
\hline $2.5 \times 10^{7}$ conidia $\mathrm{ml}^{-1}$ & 1.74 & 0.19 & & \\
\hline \multicolumn{5}{|l|}{ Combined treatment } \\
\hline $1.0 \times 10^{8}$ conidia $\mathrm{ml}^{-1}$ & 1.25 & 0.42 & 1.30 & 0.39 \\
\hline $2.5 \times 10^{7}$ conidia $\mathrm{ml}^{-1}$ & 0.12 & 0.99 & & \\
\hline \multicolumn{5}{|l|}{$\mathrm{b}$} \\
\hline \multicolumn{5}{|l|}{ Dry residue } \\
\hline $1.0 \times 10^{8}$ conidia $\mathrm{ml}^{-1}$ & 2.21 & 0.07 & 1.61 & 0.24 \\
\hline $2.5 \times 10^{7}$ conidia $\mathrm{ml}^{-1}$ & 0.72 & 0.75 & & \\
\hline \multicolumn{5}{|l|}{ Topical treatment } \\
\hline $1.0 \times 10^{8}$ conidia $\mathrm{ml}^{-1}$ & 1.67 & 0.22 & 0.70 & 0.76 \\
\hline $2.5 \times 10^{7}$ conidia $\mathrm{ml}^{-1}$ & 0.96 & 0.61 & & \\
\hline \multicolumn{5}{|l|}{ Combined treatment } \\
\hline $1.0 \times 10^{8}$ conidia $\mathrm{ml}^{-1}$ & 1.34 & 0.37 & 1.45 & 0.32 \\
\hline $2.5 \times 10^{7}$ conidia $\mathrm{ml}^{-1}$ & 0.20 & 0.98 & & \\
\hline \multicolumn{5}{|l|}{$\mathrm{c}$} \\
\hline \multicolumn{5}{|l|}{ Dry residue } \\
\hline $1.0 \times 10^{8}$ conidia $\mathrm{ml}^{-1}$ & 1.04 & 0.55 & 0.79 & 0.71 \\
\hline $2.5 \times 10^{7}$ conidia $\mathrm{ml}^{-1}$ & 0.22 & 0.97 & & \\
\hline \multicolumn{5}{|l|}{ Topical treatment } \\
\hline $1.0 \times 10^{8}$ conidia $\mathrm{ml}^{-1}$ & 0.49 & 0.88 & 0.37 & 0.93 \\
\hline $2.5 \times 10^{7}$ conidia $\mathrm{ml}^{-1}$ & 0.96 & 0.60 & & \\
\hline \multicolumn{5}{|l|}{ Combined treatment } \\
\hline $1.0 \times 10^{8}$ conidia $\mathrm{ml}^{-1}$ & 0.24 & 0.97 & 0.04 & 0.99 \\
\hline $2.5 \times 10^{7}$ conidia $\mathrm{ml}^{-1}$ & 0.31 & 0.95 & & \\
\hline
\end{tabular}

from B. bassiana-treated A. swirskii. Moreover, no deformation or moulting problems in the offspring was observed (A Midthassel pers. obs) suggesting that the fitness of the eggs produced by an infected adult female is not compromised by the pathogen.

The study on juvenile $A$. swirskii developing from egg to adult on dry residue of $B$. bassiana was intended to simulate the effect on a founding population of $A$. swirskii inoculated or dispersing into a recently treated crop. There was no significant effect on survivorship of juvenile A. swirskii on B. bassiana dry residue compared with the control treatment and mycosis was observed in a small proportion of dead mites at $1 \times 10^{8}$ conidia ml $\mathrm{ml}^{-1}$ only. This indicates that, although adult mites dispersing into a treated crop may succumb to treatment residues of $B$. bassiana, their offspring will not be affected and are therefore capable of establishing new populations. The subsequent reduced fecundity of these mites however suggest that $A$. swirskii juveniles on dry residue were infected by $B$. bassiana, but with a lighter infection, revealing sublethal effects but not causing mortality. This would most likely be due to fewer inoculum successfully invading the host.

Immature stages are often less susceptible to fungal infection due to germinating conidia being shed during ecdysis (Vey and Fargues 1977; Ugine et al. 2005). Short immature life stages, and therefore frequent ecdysis, combined with relatively low persistence of B. bassiana conidia on leaf surfaces can explain the low susceptibility of juvenile A. swirskii to this pathogen. Viability of $B$. bassiana conidia decreases gradually on leaves and persistence on top leaves has been reported to be four days (Inglis et al. 1993). As $A$. swirskii eggs, which were not affected by $B$. bassiana dry residue, hatch 1-2 days post-oviposition and the nymphs moult to the next instar every 1-2 days under optimal conditions (Lee and Gillespie 2011; Midthassel et al. 2013) the juvenile stages are able to evade pathogen invasion during the first few days postapplication and therefore survive until the conidial viability has been reduced. The effect of $B$. bassiana residue on juvenile phytoseiids has not previously been studied and these results offer the first insight into the effect of $B$. bassiana on the population-founding individuals in a treated crop.

Field studies of $B$. bassiana applications with concomitant inoculations of phytoseiid mites have largely concluded that there is no detrimental effect on the phytoseiids and deemed these BCAs as compatible (Jacobson et al. 2001; Chandler et al. 2005; Numa Vergel et al. 2011). Compatibility however does not warrant an additive or synergistic contribution to pest control. Jacobson et al. (2001) found that combining $B$. bassiana with Neoseiulus cucumeris did not improve nor disrupt thrips control in a cucumber crop and $B$. bassiana treatments in conjunction with $N$. californicus or $P$. persimilis did not improve nor disrupt 
Tetranychus urticae Koch (Acari: Tetranychidae) control in roses (Numa Vergel et al. 2011). Enhanced T. urticae control has been reported on tomato with concomitant use of $B$. bassiana and $P$. persimilis compared with either one on their own (Chandler et al. 2005) suggesting that improved control by combined treatments may be crop-specific or dependent on pest level and age distribution.

Although concomitant pest control with A. swirskii and $B$. bassiana may not be additive or synergistic, these two BCAs may complement each other in an IPM programme: A. swirskii for preventative control and $B$. bassiana as a curative treatment. When pest populations build up beyond the level where reasonable control can be expected from predatory mites, corrective applications with $B$. bassiana can be conducted followed by re-introduction of $A$. swirskii if needed. The effect of B. bassiana on other arthropod BCAs in the IPM programme must still be considered, and the potential detrimental effect of other components, such as fungicides, on B. bassiana must be taken into account. IPM programmes are complex and inconstant and there is much further work to be conducted to fully understand and optimise these control strategies.

Based on the results from the current study the susceptibility of $A$. swirskii as a physiological host for B. bassiana GHA is confirmed with slight to moderate virulence depending on exposure type. Despite the sublethal effects of $B$. bassiana on the fecundity of $A$. swirskii, these two BCAs have good potential for concomitant use in the field due to the following points: (1) no significant effect of dry residue on juvenile survival; (2) no significant effect of dry residue on fecundity; (3) no detrimental effect on the offspring of infected $A$. swirskii with respect to egg hatching, juvenile survival and sex ratio; and (4) the mortality in field conditions are generally expected to be lower than in the laboratory. Further work should focus on field compatibility of these two BCAs.

Acknowledgments The authors are grateful to Certis Europe BV for funding the research in question and to Prof Michael J Crawley and Prof Torsten Hothorn for advice on statistics. A special thanks to Amélie Midthassel for interesting discussions and inspiration.

Open Access This article is distributed under the terms of the Creative Commons Attribution 4.0 International License (http:// creativecommons.org/licenses/by/4.0/), which permits unrestricted use, distribution, and reproduction in any medium, provided you give appropriate credit to the original author(s) and the source, provide a link to the Creative Commons license, and indicate if changes were made.

\section{References}

Agboton BV, Hanna R, Onzo A, Vidal S, von Tiedemann A (2013) Interactions between the predatory mite Typhlodromalus aripo and the entomopathogenic fungus Neozygites tanajoae and consequences for the suppression of their shared prey/host Mononychellus tanajoa. Exp Appl Acarol 60:205-217

Aqueel MA, Leather SR (2013) Virulence of Verticillium lecanii (Z.) against cereal aphids; does timing of infection affect the performance of parasitoids and predators? Pest Manag Sci 69:493-498

Baxter IH (2008) Entomopathogen based autodissemination for the control of Plodia interpunctella (Hübner) - an examination of the critical components. PhD Thesis, University of Southampton

Bugeme DM, Maniania NK, Knapp M, Boga HI (2008) Effect of temperature on virulence of Beauveria bassiana and $\mathrm{Me}$ tarhizium anisopliae isolates to Tetranychus evansi. Exp Appl Acarol 46:275-285

Buitenhuis R, Shipp L, Scott-Dupree C (2010) Intra-guild vs extra-guild prey: effect on predator fitness and preference of Amblyseius swirskii (Athias-Henriot) and Neoseiulus cucumeris (Oudemans) (Acari: Phytoseiidae). B Entomol Res 100:167-173

Calvo FJ, Bolckmans K, Belda JE (2009) Development of a biological control-based Integrated Pest Management method for Bemisia tabaci for protected sweet pepper crops. Entomol Exp Appl 133:9-18

Calvo FJ, Bolckmans K, Belda JE (2011) Control of Bemisia tabaci and Frankliniella occidentalis in cucumber by Amblyseius swirskii. BioControl 56:185-192

Castagnoli M, Liguori M, Simoni S, Duso C (2005) Toxicity of some insecticides to Tetranychus urticae, Neoseiulus californicus and Tydeus californicus. BioControl 50:611-622

Chandler D, Davidson G, Pell JK, Ball BV, Shaw K, Sunderland KD (2000) Fungal biocontrol of Acari. Biocontrol Sci Techn 10:357-384

Chandler D, Davidson G, Jacobson RJ (2005) Laboratory and glasshouse evaluation of entomopathogenic fungi against the two-spotted spider mite, Tetranychus urticae (Acari: Tetranychidae), on tomato, Lycopersicon esculentum. Biocontrol Sci Technol 15:37-54

Chow A, Chau A, Heinz KM (2010) Compatibility of Amblyseius (Typhlodrompis) swirskii (Athias-Henriot) (Acari: Phytoseiidae) and Orius insidiosus (Hemiptera: Anthocoridae) for biological control of Frankliniella occidentalis (Thysanoptera: Thripidae) on roses. Biol Control 53:188-196

Cock MJW, van Lenteren JC, Brodeur J, Barratt BIP, Bigler F, Bolckmans K, Cônsoli FL, Haas F, Mason PG, Parra JRP (2010) Do new access and benefit sharing procedures under the convention on biological diversity threaten the future of biological control? BioControl 55:199-218 
Crawley MJ (2007) The R Book. John Wiley and Sons Ltd, Chichester

da Silva MZ, Sato ME, de Oliveira CAL, Nicastro RL (2015) Interspecific interactions involving Neoseiulus californicus (Acari: Phytoseiidae) and Agistemus brasiliensis (Acari: Stigmaeidae) as predators of Brevipalpus phoenicis (Acari: Tenuipalpidae). Exp Appl Acarol 65:319-329

de Faria MR, Wraight SP (2007) Mycoinsecticides and Mycoacaricides: A comprehensive list with worldwide coverage and international classification of formulation types. Biol Control 43:237-256

Dennehy TJ, Farnham AW, Denholm I (1993) The microimmersion bioassay: a novel method for topical application of pesticides to spider mites. Pestic Sci 39:47-54

Dogramaci M, Arthurs S, Chen J, McKenzie CL, Irrizary F, Osborne L (2011) Management of chilli thrips Scirtothrips dorsalis (Thysanoptera: Thripidae) on peppers by Amblyseius swirskii (Acari: Phytoseiidae) and Orius insidiosus (Hemiptera: Anthocoridae). Biol Control 59:340-347

Duso C, Malagnini V, Pozzebon A, Castagnoli M, Liguori M, Simoni S (2008) Comparative toxicity of botanical and reduced-risk insecticides to Mediterranean populations of Tetranychus urticae and Phytoseiulus persimilis (Acari Tetranychidae, Phytoseiidae). Biol Control 47:16-21

Faria M, Wraight SP (2001) Biological control of Bemisia tabaci with fungi. Crop Prot 20:767-778

Hothorn T, Bretz F, Westfall P (2008) Simultaneous inference in general parametric models. Biometrical J 50:346-363

Humber RA (1997) Fungi: identification. In: Lacey LA (ed) Manual of techniques in insect pathology. Academic Press, San Diego, CA, pp 153-185

Inglis GD, Goettel MS, Johnson DL (1993) Persistence of the entomopathogenic fungus, Beauveria bassiana, on phylloplanes of crested wheatgrass and alfalfa. Biol Control $3: 258-270$

Inglis GD, Goettel MS, Butt TM, Strasser H (2001) Use of hyphomycetous fungi for managing insect pests. In: Butt TM, Jackson CW, Magan N (eds) Fungi as biocontrol agents: progress, problems and potential. CABI Publishing, Wallingford, pp 23-70

Jacobson RJ, Chandler D, Fenlon J, Russell KM (2001) Compatibility of Beauveria bassiana (Balsamo) Vuillemin with Amblyseius cucumeris Oudemans (Acarina: Phytoseiidae) to control Frankliniella occidentalis Pergande (Thysanoptera: Thripidae) on cucumber plants. Biocontrol Sci Technol 11:391-400

Labbe RM, Gillespie DR, Cloutier C, Brodeur J (2009) Compatibility of an entomopathogenic fungus with a predator and a parasitoid in the biological control of greenhouse whitefly. Biocontrol Sci Technol 19:429-446

Lee HS, Gillespie DR (2011) Life tables and development of Amblyseius swirskii (Acari: Phytoseiidae) at different temperatures. Exp Appl Acarol 53:17-27

Liu H, Skinner M, Brownbridge M, Parker BL (2003) Characterization of Beauveria bassiana and Metarhizium anisopliae isolates for management of tarnished plant bug, Lygus lineolaris (Hemiptera: Miridae). J Invertebr Pathol 82:139-147

Ludwig SW, Oetting RD (2001) Susceptibility of natural enemies to infection by Beauveria bassiana and impact of insecticides on Ipheseius degenerans (Acari: Phytoseiidae). J Agric Urban Entomol 18:169-178
Malais MH, Ravensberg WJ (2003) Knowing and recognizing: the biology of glasshouse pests and their natural enemies. Koppert Biological Systems

Mascarin GM, Kobori NN, Quintela ED, Delalibera I (2013) The virulence of entomopathogenic fungi against Bemisia tabaci biotype B (Hemiptera: Aleyrodidae) and their conidial production using solid substrate fermentation. Biol Control 66:209-218

Medd N, GreatRex M (2014) An evaluation of three predatory mite species for the control of greenhouse whitefly (Trialeurodes vaporariorum). Pest Manag Sci 70:1492-1496

Messelink GJ, van Steenpaal SEF, Ramakers PMJ (2006) Evaluation of phytoseiid predators for control of western flower thrips on greenhouse cucumber. BioControl 51:753-768

Messelink GJ, van Maanen R, van Holstein-Saj R, Sabelis MW, Janssen A (2010) Pest species diversity enhances control of spider mites and whiteflies by a generalist phytoseiid predator. BioControl 55:387-398

Messelink GJ, Bloemhard CMJ, Sabelis MW, Janssen A (2011) Hyperpredation by generalist predatory mites disrupts biological control of aphids by the aphidophagous gall midge Aphidoletes aphidimyza. Biol Control 57:246-252

Midthassel A, Leather SR, Baxter IH (2013) Life table parameters and capture success ratio studies of Typhlodromips swirskii (Acari: Phytoseiidae) to the factitious prey Suidasia medanensis (Acari: Suidasidae). Exp Appl Acarol 61:69-78

Momen FM, Abdel-Khalek A (2009) Cannibalism and intraguild predation in the phytoseiid mites Typhlodromips swirskii, Euseius scutalis and Typhlodromus athiasae (Acari: Phytoseiidae). Acarina 17:223-229

Numa Vergel SJ, Bustos RA, Rodriguez CD, Cantor RF (2011) Laboratory and greenhouse evaluation of the entomopathogenic fungi and garlic-pepper extract on the predatory mites, Phytoseiulus persimilis and Neoseiulus californicus and their effect on the spider mite Tetranychus urticae. Biol Control 57:143-149

Pozzebon A, Duso C (2010) Pesticide side-effects on predatory mites: the role of trophic interactions. In: Sabelis MW, Bruin J (eds) Trends in acarology: proceedings of the 12th international congress. Springer, Netherlands, pp 465-469

Seiedy M, Saboori A, Allahyari H (2012) Interactions of two natural enemies of Tetranychus urticae, the fungal entomopathogen Beauveria bassiana and the predatory mite, Phytoseiulus persimilis. Biocontrol Sci Technol 22:873-882

Seiedy M, Tork M, Deyhim F (2015) Effect of the entomopathogenic fungus Beauveria bassiana on the predatory mite Amblyseius swirskii (Acari: Phytoseiidae) as a nontarget organism. Syst Appl Acarol 20:241-250

Shah PA, Pell JK (2003) Entomopathogenic fungi as biological control agents. Appl Microbiol Biotechnol 61:413-423

Shipp JL, Zhang Y, Hunt DWA, Ferguson G (2003) Influence of humidity and greenhouse microclimate on the efficacy of Beauveria bassiana (Balsamo) for control of greenhouse arthropod pests. Environ Entomol 32:1154-1163

Shipp L, Kapongo JP, Park H-H, Kevan P (2012) Effect of beevectored Beauveria bassiana on greenhouse beneficials under greenhouse cage conditions. Biol Control 63:135-142

R Core Team (2012) R: A language and environment for statistical computing. R Foundation for Statistical Computing, Vienna. http://www.R-project.org/ 
Torrado-Leon E, Montoya-Lerma J, Valencia-Pizo E (2006) Sublethal effects of Beauveria bassiana (Balsamo) Vuillemin (Deuteromycotina: Hyphomycetes) on the whitefly Bemisia tabaci (Gennadius) (Hemiptera: Aleyrodidae) under laboratory conditions. Mycopathologia 162:411-419

Ugine TA, Wraight SP, Sanderson JP (2005) Acquisition of lethal doses of Beauveria bassiana conidia by western flower thrips, Frankliniella occidentalis, exposed to foliar spray residues of formulated and unformulated conidia. J Invertebr Pathol 90:10-23

van Lenteren JC (2012) The state of commercial augmentative biological control: plenty of natural enemies, but a frustrating lack of uptake. BioControl 57:1-20

Vey A, Fargues J (1977) Histological and ultrastructural studies of Beauveria bassiana infection in Leptinotarsa decemlineata larvae during ecdysis. J Invertebr Pathol 30:207-215

Wittman EJ, Leather SR (1997) Compatability of Orius laevigatus Fieber (Hemiptera: Anthocoridae) with Neoseiulus (Amblyseius) cucumeris Oudemans (Acari: Phytoseiidae) and Iphiseius (Amblyseius) degenerans Berlese (Acari: Phytoseiidae) in the biocontrol of Frankliniella occidentalis Pergande (Thysanoptera: Thripidae). Exp Appl Acarol 21:523-538

Wraight SP, Carruthers RI, Jaronski ST, Bradley CA, Garza CJ, Galaini-Wraight S (2000) Evaluation of the entomopathogenic fungi Beauveria bassiana and Paecilomyces fumosoroseus for microbial control of the silverleaf whitefly, Bemisia argentifolii. Biol Control 17:203-217
Zimmermann G (2007) Review on safety of the entomopathogenic fungi Beauveria bassiana and Beauveria brongniartii. Biocontrol Sci Technol 17:553-596

Audun Midthassel has completed a $\mathrm{PhD}$ on the interactions between a predatory mite and its factitious prey at Imperial College London. He is currently working on development of biopesticides and biorational crop protection strategies at the IPM R\&D facilities of Certis Europe in France.

Simon R. Leather is professor of entomology at Harper Adams University. His main research interests are insect-plant interactions and integrated pest management in agricultural, horticultural and forest systems. He works mainly on aphids, beetles and lepidoptera.

Denis J. Wright is professor of pest management at Imperial College London. His areas of interest include resistance to $\mathrm{Bt}$ toxins, crop plant-insect pest-natural enemy interactions and the use of biological control agents as biopesticides.

Ian H. Baxter has completed a $\mathrm{PhD}$ on the chemical ecology and entomopathogens of stored products pests. He has since had a variety of roles in applied entomology from academic research to commercial crop protection. Currently, he works at Certis Europe as a product development manager with focus on developing biorational crop protection technologies. 